\title{
Determiner spreading as DP-predication
}

\author{
Article
}

Accepted Version

Panagiotidis, E. P. and Marinis, T. (2011) Determiner

spreading as DP-predication. Studia Linguistica, 65 (3). pp. 268-298. ISSN 0039-3193 doi: https://doi.org/10.1111/j.14679582.2011.01186.x Available at https://centaur.reading.ac.uk/17258/

It is advisable to refer to the publisher's version if you intend to cite from the work. See Guidance on citing.

To link to this article DOI: http://dx.doi.org/10.1111/j.1467-9582.2011.01186.x

Publisher: Wiley-Blackwell

Publisher statement: The definitive version is available at wileyonlinelibrary.com

All outputs in CentAUR are protected by Intellectual Property Rights law, including copyright law. Copyright and IPR is retained by the creators or other copyright holders. Terms and conditions for use of this material are defined in the End User Agreement.

\section{www.reading.ac.uk/centaur}

\section{CentAUR}

Central Archive at the University of Reading

Reading's research outputs online 


\title{
DETERMINER SPREADING AS DP-PREDICATION* E. Phoevos Panagiotidis, University of Cyprus Theodore Marinis, University of Reading
}

\begin{abstract}
Determiner Spreading (DS) occurs in adjectivally modified nominal phrases comprising more than one definite article, a phenomenon that has received considerable attention and has been extensively described in Greek. This paper discusses the syntactic properties of DS in detail and argues that DS structures are both arguments and predication configurations involving two DPs. This account successfully captures the word-order facts and the distinctive interpretation of DS, while also laying the groundwork towards unifying it with other structures linking two DPs in a predicative relation.
\end{abstract}

\section{INTRODUCTION}

Determiner Spreading ('DS' henceforth) is a nominal construction in Modern Greek ('Greek' henceforth), in which more than one definite article can appear in front of the noun phrase's adjectives. ${ }^{1}$ DS is actually attested through most of the history of the Greek language, going back to at least Herodotus ( $5^{\text {th }}$ century BC), and displays distinctive interpretive characteristics. ${ }^{2}$ DS prototypically involves a D(eterminer)-A(djective)- 
$\mathrm{D}$ (eterminer)-N(oun) order or a $\mathrm{D}$ (eterminer)-N(oun)-D(eterminer)A(djective) one, and it exists alongside 'ordinary' adjectival modification, displaying a (D)-A-N or an N-A order. The phenomenon is intriguing for a number of reasons: why do these two different ways of 'doing' adjectival modification exist? What are their interpretive differences? How can we explain noun phrase-internal determiners and a single noun in an analysis adhering to the DP-hypothesis (popularised by Abney, 1987 - but of many progenitors)?

This paper will examine Determiner Spreading from a syntactic point of view and touch upon its semantics only in order to clarify matters of structure. Insightful semantic approaches to the phenomenon, although not fully compatible with the syntactic analysis put forward here, are provided in Larson (2004), Kolliakou (2003; 2004) and Campos \& Stavrou (2004). In this paper we will argue that DS is a DP-predication structure. More specifically, we claim that a DS structure is a DP with a DP specifier, the subject of predication; the whole constituent serves both as an argument and as a predication structure.

The paper is organised as follows: Section 2 describes the properties of DS; Section 3 reviews previous analyses of the phenomenon; Section 4 presents our own analysis and shows how, with minimal assumptions, it correctly accounts for the Greek facts; finally, a summary and conclusions are given in Section 5. 


\section{THE DATA}

DS is a type of adjectival modification that involves the use of multiple definite articles preceding adjectives and the noun. Moreover, in DS only definite articles may precede adjectives and the noun. This section will present the distributional properties of DS, that is the word order facts (in subsection 2.1), as well as the interpretation of DS (in subsection 2.2).

\subsection{Possible word orders with DS}

With DS several word orders are possible. As far as the position of one adjective relative to that of the noun is concerned, there are two possible word orders: Determiner-Noun-Determiner-Adjective (D-N-D-A), as shown in (1) and Determiner-Adjective-Determiner-Noun (D-A-D-N), as shown in (2). ${ }^{3}$

(a) To spiti to meghalo

the house the big

(b) *(*Ena) spiti to meghalo

a / one house the big

(2) (a) To meghalo to spiti. 
the big the house

(b) $*(*$ Ena $) \quad$ meghalo to spiti.

a / one big the house

'The big house'

When more than one adjective is present in DS, then all the possible combinations of constituents inside the nominal phrase are grammatical, provided that all adjectives as well as the noun are preceded by definite articles. Thus, in the case of two adjectives and a noun, all the $3 !=6$ possible combinations are grammatical, as shown in (3a-f) below.
(a) To meghalo to petrino to spiti.
the big the of.stone the house
(b) To meghalo to spiti to petrino.
the big the house the of.stone
(c) To petrino to spiti to meghalo.
the of.stone the house the big
(d) To petrino to meghalo to spiti
the of.stone the big the house
(e) To spiti to meghalo to petrino.
the house the big the of.stone
(f) To spiti to petrino to meghalo. 
the house the of.stone the big

'The big stone house.'

The data in (3) above may give the impression that word order is free under DS, to the point of this structure appearing flat or even nonconfigurational, which will actually be claimed in section 3.4 to be far from true. For the time being, having just presented the freedom of word order within DS constructions, let's turn to some word order restrictions at play.

In non-DS ('monadic' in Kolliakou, 2003; 2004) Greek nominal phrases involving adjectival modification and headed by a definite article, adjectives are always prenominal, as shown in (4) below.

(a) To meghalo (petrino) spiti.

The big of.stone house

(b) *To spiti meghalo (petrino).

The house big of.stone

'The big stone house.'

Moreover, in non-DS nominal phrases, the relative order of the adjectives tends to be rigid and is governed by restrictions related to their type (Cinque, 1994; Stavrou, 1996 and 1999 for Greek).

Regarding DS, a first prominent characteristic of the construction is the following: not all adjectives need be preceded by an article, the noun can be articleless, too. In this case, ordering freedom is restricted in two ways: 
First, if one of the adjectives is not preceded by an article, it cannot appear postnominally, as shown in (5); contrast (5a) and (5b) below with (3e) above.

(a) $*$ To spiti meghaloto petrino.

The house big the of.stone

(b) *To spiti to meghalo petrino.

The house the big of.stone

'The big stone house.'

Second, and complementing the state of affairs exemplified under (5), if the noun is not preceded by an article, it is obligatory for it to immediately follow an adjective, as in (6). Interestingly, sequences like to petrino spiti in (6a) and to meghalo spiti in (6b) look like fully-fledged monadic DPs.

(6) (a) To meghalo to petrino spiti.

The big the of.stone house

(b) To meghalo spiti to petrino.

The big house the of.stone

'The big stone house.'

(c) To meghalo petrino spiti to palio 
the big stone house the old

'The old big stone house'

The statements in (7) recapitulate the word order state of affairs in DS:

(a) no indefinite articles can be involved in a DS noun phrase;

(b) if all adjectives and the noun are preceded by the definite article, ordering is free;

(c) if the noun is not preceded by an article, it must be preceded by an adjective that is in turn preceded by an article;

(d) adjectives can be used postnominally if they are preceded by a definite article.

\subsection{On the interpretation of $D S$}

Noun phrases with DS are interpreted differently from (monadic) definite noun phrases, however subtle the difference. As Alexiadou \& Wilder (1998), Manolessou (2000: Ch. 4), Kolliakou (1998; 2003; 2004) and Campos \& Stavrou (2004) point out, DS is not semantically identical to adjectival modification with a single definite article. Adjectival modification within a monadic DP may have either a restrictive or a non-restrictive interpretation, as in (8a) below; on the other hand, DS often receives only a 
restrictive reading, i.e. DS “"narrows down' a given set of referents by picking out a proper subset of it" (Kolliakou 1998: 4-5; 2004: 268-276). This is illustrated in (8b) below. ${ }^{4}$

(a) $\mathrm{O}$ dhiefthindis dhilose oti $\boldsymbol{i}$ ikani erevnites the manager declared that the competent researchers tha eprepe na apolithun FUT had.to SUBJ fired. $3^{\mathrm{RD}} \mathrm{PL}$ 'The manager declared that the competent researchers should be fired.' (restrictive or non-restrictive interpretation)

(b) $\mathrm{O}$ dhiefthindis dhilose oti $\boldsymbol{i}$ ikani $\boldsymbol{i}$ erevnites the director declared that the competent the researchers tha eprepe na apolithun. FUT had.to SUBJ fired. $3^{\mathrm{RD}} \mathrm{PL}$ 'The manager declared that just the competent researchers should be fired.' (restrictive interpretation strongly preferred)

In (8a) above, an adjectivally modified definite noun phrase may have either of two principal interpretations, a non-restrictive interpretation or a restrictive one. In the non-restrictive interpretation, we have information about only one group of researchers, those who should be fired (for instance, due to financial difficulties of the company) and who are also characterised 
as competent; thus, there are no cues as to whether there is another group of researchers who should not be fired: $i$ ikani erevnites ('the competent researchers') describes a salient set of competent researchers.

On the other hand, in the restrictive interpretation of the DS noun phrase in (8b), a set of competent researchers is singled out from a larger set of researchers, a superset, and only the competent ones should be fired (maybe because they are involved in some secret plot against the company). In the restrictive interpretation, it is implied that other researchers (who, for instance, are not competent and therefore not dangerous for the company) should not be fired. Under the restrictive interpretation, the nominal structure with DS, say D-A-D-N ('i ikani $i$ erevnites'), refers to a proper subset of a set denoted by D-N ('i erevnites').

Now, as Manolessou (2000) observes, ${ }^{5}$ although the restrictive interpretation is clearly the preferred one in cases like (8b), a non-restrictive interpretation is also possible with DS, if properly contextualised. Moreover, in the ambiguous sentence (8a), prosody may be used to disambiguate between the two interpretations. If the adjective is stressed, the restrictive interpretation is favoured here as well. ${ }^{6}$ Therefore, the restrictive reading is only one of the possible interpretations for DS, albeit the preferred one in most contexts.

Following Manolessou (2000), let us now zoom into the possible non-restrictive interpretation of DS, as in the contexts in (9) below: 
(9)

a. vyike exo $\mathrm{s}$ [ton krio tonkero].

went-out out in the cold the weather

'S/he went out in the cold weather.'

b. Ti thelun [ta kala ta pedia]?

What want the good the children

'What do the good children want?'

c. Bike $\mathrm{s}$ [to kenuryo (tis) to aftokinito] ki efiye

got.in. ${ }^{\mathrm{ST}} \mathrm{SG}$ in the new hers the car and left

'She got into the/her new car and left.'

Of course, given the discussion of example (3) above, the D-N-D-A orders ton kero ton krio ('the cold weather') and ta pedhia ta kala ('the good children'). However, the above examples cannot be naturally construed with restrictive readings. (9a) can be uttered plainly if the weather is cold outside, not necessarily only if cold weather is understood as a subset, say a special case, of types of weather. Turning to the plural DS constituent in (9b), when addressing the children in question, which is a pragmatically felicitous usage of this sentence, the speaker does not mean to single out the set of good ones out of a salient set of children. Both cases represent run-of-the-mill usage and in all of them restrictive readings are strongly dispreferred. In this respect, (9c) is perhaps the most revealing example, in the sense that the 
constituent to kenuryo to aftokinito ('the new car') may indeed be read in a restrictive way, picking out the new car out of a set of cars; nevertheless, it is also perfectly possible to use it even if just one car exists, which also happens to be a new one. The point emerging here is that DS does have a special interpretation, but not necessarily a restrictive one.

As Manolessou (2000) and Campos \& Stavrou (2004) point out, the interpretation of the DS noun phrases in (9) is predicative. Nevertheless, this is not the whole story, as 'ordinary' adjectival modification can also be predicative, e.g. a white elephant $\approx$ an elephant (that) is white (Partee 1995; Larson 1999). Hence, we have to be more precise about the predicative character of DS while considering the restrictive interpretations available for it; in section 4 we will do so and claim that DS involves DP predication: it is a nominal constituent where one DP is predicated of another. So, in principle, DS is different from 'ordinary' adjectival modification because the latter may involve picking out the intersection of two sets (Partee 1995 for a classic overview), denoted by the predicate adjective and the predicate noun respectively. In contrast, Determiner Spreading necessarily denotes the intersection of two sets, respectively denoted by an elliptical DP containing the adjective and a DP containing the noun, in its simplest manifestation. The importance of this predicative interpretation and its relation to the restrictive one (in fact the latter will be shown to be a subcase of the former) will be further explored in section $4.5 .^{7}$ 


\section{PREVIOUS ANALYSES}

A number of analyses have been offered to account for the phenomenon of DS; we will now review four of them: Androutsopoulou (1994; 1995), Alexiadou \& Wilder (1998), Giusti (2003) and Campos \& Stavrou (2004). ${ }^{8}$ We concentrate on them because these analyses offer well-articulated syntactic accounts of the phenomenon within the framework followed here, Principles and Parameters aspiring towards Minimalism. ${ }^{9}$ It is also worth noting that each of them is informed by major recent developments in syntactic theory; hence: Androutsopoulou $(1994 ; 1995)$ by the proposals that a greater number of functional categories (may) exist, besides the better studied C(omplementiser), I(nflection) and D(eterminer); Alexiadou \& Wilder (1998) by Kayne's (1994) Antisymmetry Hypothesis; Giusti (2003) by Chomsky's (1993) Bare Phrase Structure; Campos \& Stavrou (2004) by Bowers' (1993) and Den Dikken's (1998) postulation of a Pred(ication) category.

\subsection{Androutsopoulou (1994; 1995)}

Androutsopoulou $(1994 ; 1995)$ takes DS to be akin to Semitic 'definiteness spreading' (Ritter, 1991; Siloni, 1997; Dobrovie-Sorin, 2000). She claims that the 'extra' definite articles in the structure of DS are not of the category 
$\mathrm{D}$, but rather spell-outs of a definiteness feature [+def], which is argued not to be a semantic feature, but a syntactic one. This is in the spirit of Delsing's (1988) analysis for Mainland Scandinavian, where 'intermediate' articles look like the definite Determiner, but are not (pace Hellan, 1986 and Taraldsen, 1990). ${ }^{10}$ According to Androutsopoulou, every definite article in DS heads its own functional agreement projection, called Definite Phrase (DefP), hosting agreement features (gender, number, case) and the [+def] feature. Although DefPs host the feature [+def], the locus of definiteness and referentiality is D and not the 'intermediate' articles, heads of DefPs. Finally, APs intervene in the projection line between D and N, à la Abney (1987) and Radford (1993). The 'initial' structure being the one under (10), movement to (the highest) SpecDefP derives the different word orders, an instance thereof illustrated in (11) below.

(10) DS (=3a) in Androutsopoulou's account 


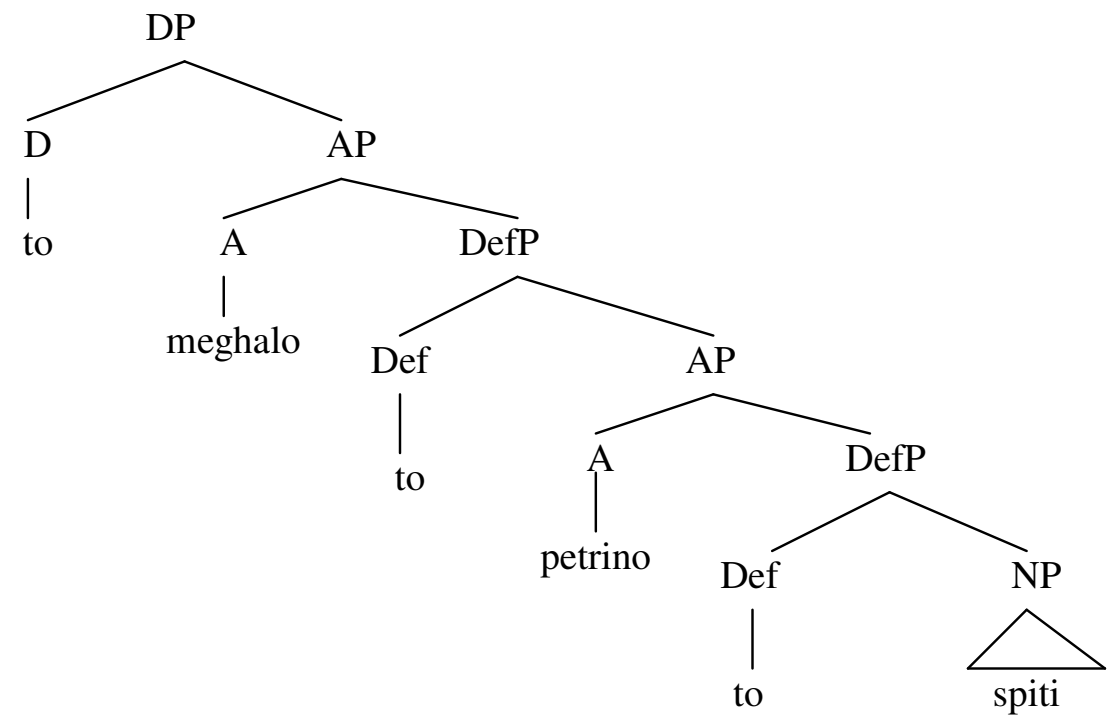

(11) DS with derived order (= 3b) in Androutsopoulou's account

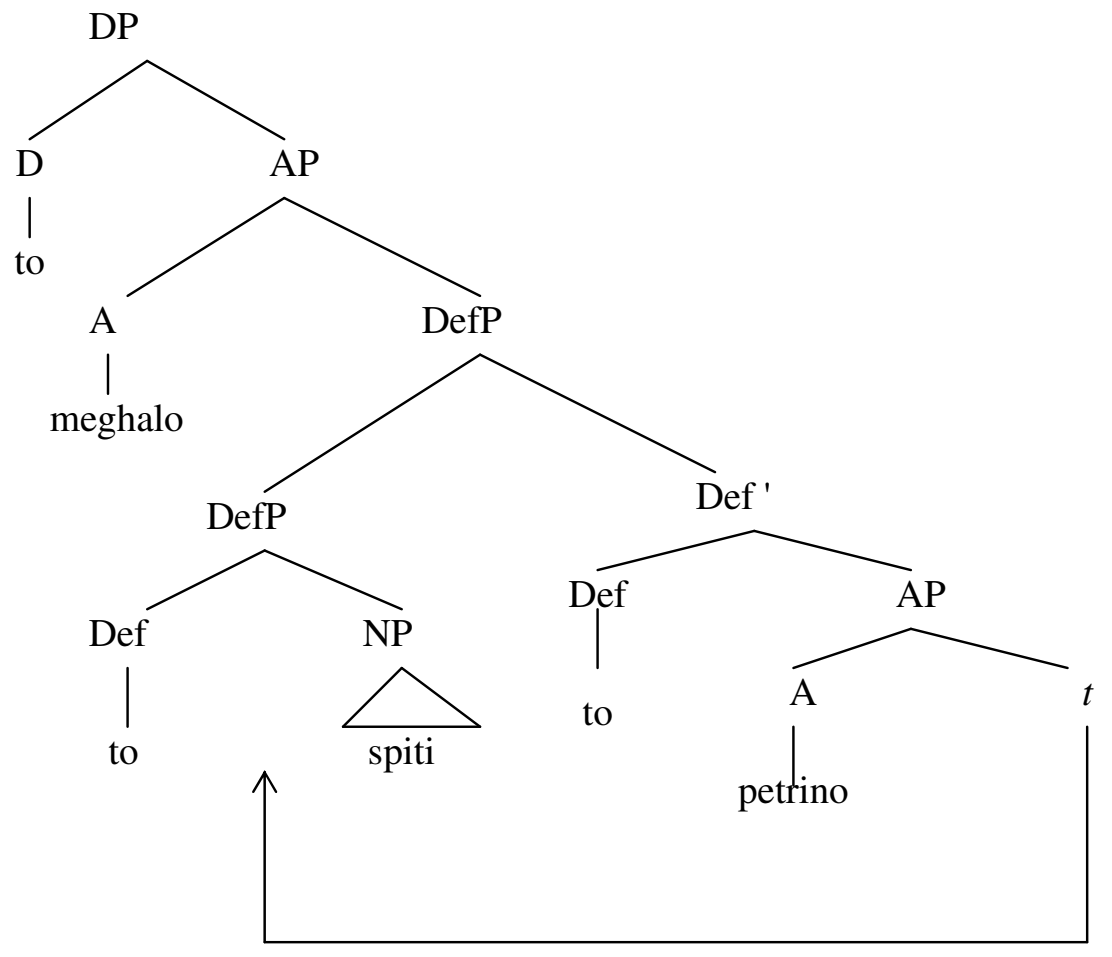


Androutsopoulou's analysis can capture all the different orderings under (3) either with a series of movement operations to the highest SpecDefP or to SpecDP, or with the possibility to merge the two adjectives in different orders.

Even so, the question of what drives such XP movement operations remains unresolved; besides this, the analysis leaves a number of open questions regarding the nature of Def:

a. What happens in cases such as (6), where articles ('Def heads') can be missing?

b. Why are Def heads morphologically identical to Ds (unlike, for instance, Scandinavian D den and the definite suffix $-e n)$ ?

c. How is their [def] feature, a syntactic and not a semantic one, interpreted at LF, especially in view of the predicative / restrictive interpretation of DS?

d. Are Def heads present in other syntactic environments in Greek ? $^{11}$

\subsection{Alexiadou \& Wilder (1998)}

An account in a different vein is that by Alexiadou and Wilder (1998), who take the predicative / restrictive interpretation of DS as their starting point. They go on to analyse DS as reduced relative clauses, as predicative structures. The analysis for relative clauses they adopt is the one in Kayne (1994), namely that relative clauses are made up from a D head taking a CP 
(clausal) complement: [DP $\mathrm{D}_{\text {the }}[\mathrm{CP} \text { [NP stone house }]_{\mathrm{j}}\left[\mathrm{C}\right.$ that [IP I saw $\left.\left.\left.\mathrm{t}_{\mathrm{j}}\right]\right]\right]$. Hence, Alexiadou and Wilder's proposed structure for DS is that of a reduced relative clause, complete with an embedded full $\mathrm{CP}$ :

$$
\text { [DP } \left.\mathrm{D}\left[\mathrm{CP} \mathrm{AP}_{\mathrm{i}}\left[\mathrm{C} \varnothing\left[\mathrm{IP} \alpha t_{\mathrm{i}}\right]\right]\right]\right]
$$

At the heart of DS there is an IP structure with an AP predicated of a subject $\alpha$. The predicate AP moves to the SpecCP, adjacent to D, and the order D-A- $\alpha$ obtains. Now, the surface order of constituents depends on the identity of the subject $\alpha$. Thus, if $\alpha$ is a simple DP, then a 'basic' D-A-D-N order ensues, as in to meghalo to spiti in (13) below. Movement of the subject to spiti to a higher position, such as SpecDP, yields the D-N-D-A order.

When the subject $\alpha$ is a DS structure itself, then recursion follows, yielding [DP $\left.\left.\mathrm{D}\left[\mathrm{CP}_{\mathrm{CP}} \mathrm{AP}_{\mathrm{i}} \varnothing\left[\mathrm{CIP}\left[\mathrm{DP} \mathrm{D}\left[\mathrm{CP}_{\mathrm{CP}} \mathrm{AP}_{\mathrm{j}}\left[\mathrm{C} \varnothing\left[{ }_{\mathrm{IP}} \mathrm{DP} t_{\mathrm{j}}\right]\right]\right]\right] t_{\mathrm{i}}\right]\right]\right]\right]$ e.g. to meghalo to petrino to spiti. By way of illustration, consider the phrase marker for to meghalo to spiti in (13) below.

(13) $D-A-D-N$ as [DP $\left.D\left[{ }_{\mathrm{CP}} A P_{i}\left[\mathrm{C} \varnothing\left[\mathrm{IP} D P \mathrm{t}_{i}\right]\right]\right]\right]$ 


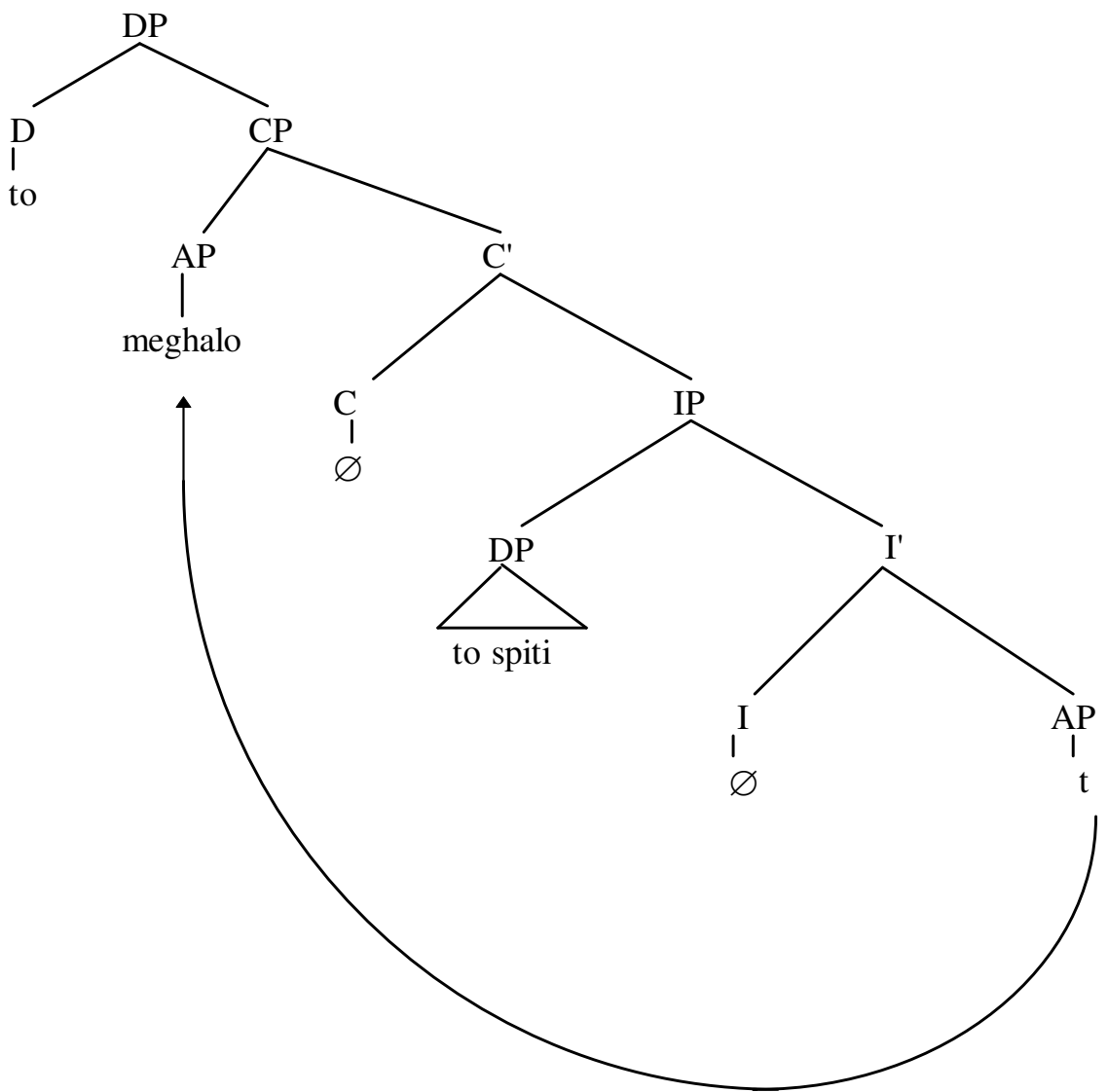

In order to account for word order variations, the analysis allows the embedded subject to spiti to move to the highest position using the specifiers of the respective DPs as escape hatches. Alexiadou and Wilder's proposal has the virtue of acknowledging both the restrictive interpretation and the predicative nature of DS, plausibly capturing them as resulting from the presence of a reduced relative inside a DP. At the same time, the structure proposed is quite complex in the crucial sense that it radically differs from that of 'monadic' DPs: Alexiadou and Wilder posit a verbless clause in the complement of D as well as a set of constraints and movement 
operations lacking clear motivation. Furthermore, under this analysis, D-AD-N appears to be the default order with D-N-D-A order as the derived one, resulting from a further movement operation to the specifier of the matrix DP. However, there is no evidence that either D-A-D-N or D-N-D-A constitutes a default order. ${ }^{12}$

\subsection{Giusti (2003)}

Giusti's analysis is similar to Alexiadou \& Wilder's - but without the proposed structure containing a $\mathrm{CP}$ constituent. In this account, the D-A is a constituent, more specifically, an AP agreeing for definiteness. This agreeing AP is generated at the specifier of a YP situated between D and N, where all APs are taken to be merged. The D-N-D-A order is derived by movement of the $\mathrm{N}$ head over the AP to a higher head position $\mathrm{X}$, as shown in (14) below, an operation that could be claimed to take place for independent purposes (Cinque, 1994). The D-A-D-N order is derived by a further optional XP movement operation of the 'definite' AP (D-A) to the specifier of DP. 


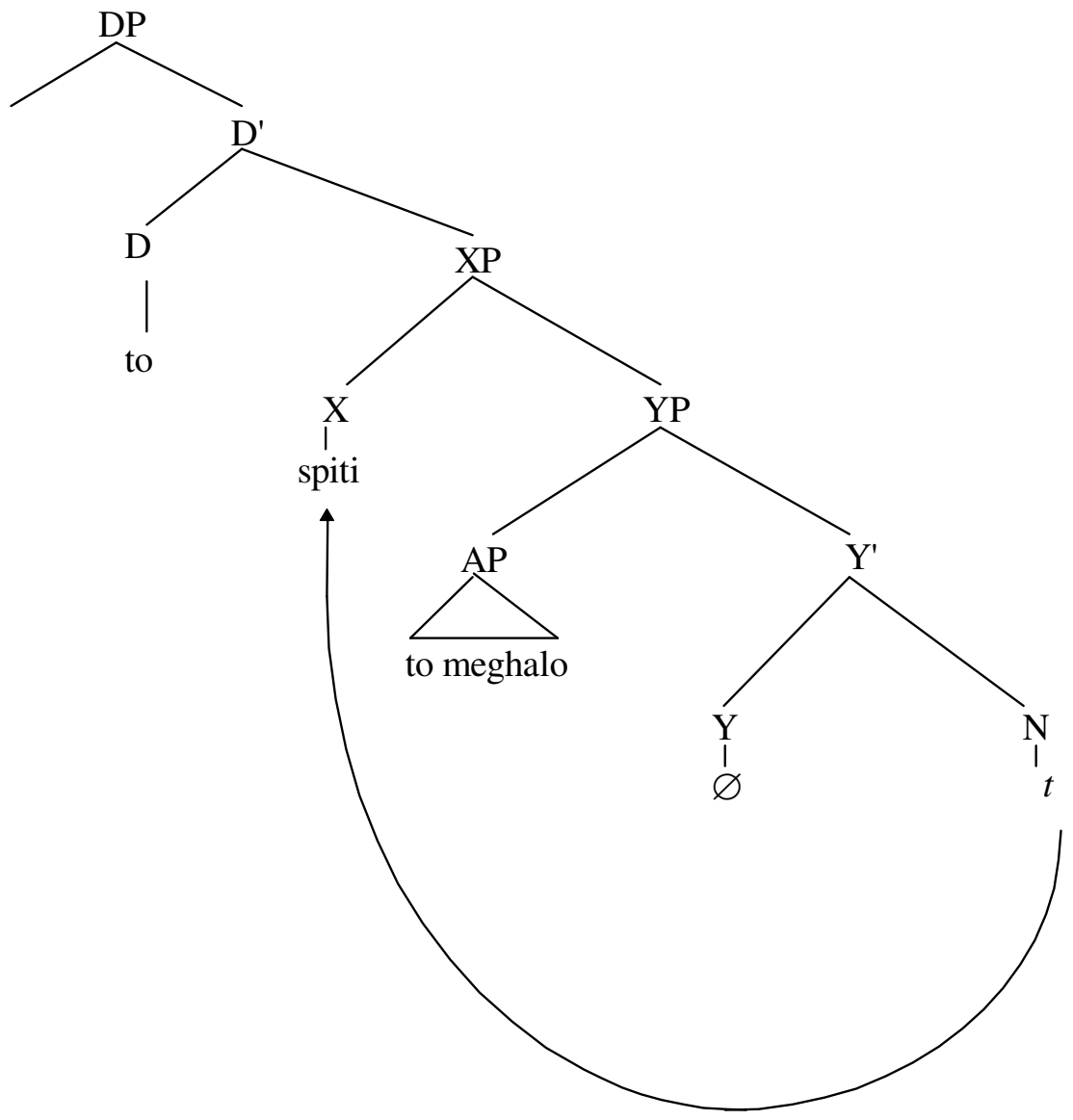

One of the consequences is that the D-N-D-A order is again postulated to be the basic one, something that is in tune with the situation in Semitic and the situation in older forms of Greek - as noted in footnote 12 but unmotivated for Modern Greek. The D-A-D-N order is also argued to involve SpecDP, a position that has independently been shown to be particularly 'active' in Greek (see also section 4.2).

Giusti's analysis however does not account for the special restrictive / predicative interpretation of DS, as such an interpretive effect does not seem to have anything to do with the categories $\mathrm{X}$ and $\mathrm{Y}$. Another issue is 
with the status of the N-to-X movement, posited in Cinque (1994) to account for the Noun-Adjective orders in Romance. When it comes to whether this operation takes place in Greek, opinions are split between

a) this head-movement operation being short-distance, overtly targeting a much lower head, Num, right above the (nP-)NP shell (Panagiotidis, 2000) and

b) such a head-movement operation not existing at all in the language (Alexiadou \& Stavrou, 1998), see Stavrou (1996) for discussion.

\subsection{Campos \& Stavrou (2004)}

The analysis of Determiner Spreading in Campos \& Stavrou (2004) builds on that of Alexiadou \& Wilder (1998). Besides doing away with the proposal of a reduced $\mathrm{CP}$ at the heart of a DS structure, the main merits of Campos \& Stavrou's analysis are

a) clearly establishing the predicative nature of Determiner Spreading, harking back not only to Alexiadou \& Wilder (1998) but also to Manolessou (2000), and

b) identifying the second Determiner in a DS as the predication operator itself.

A further advantage is their identifying the existence of Determiner Spreading as a predicative structure in languages beyond Greek: Aromanian

(a Southern Balkan Romance language), Albanian - with some 
morphological complications - and Romanian. They also argue that the D$\mathrm{N}-\mathrm{D}-\mathrm{A}$ order is the base one and that in these orders the adjective is a predicative AP. Finally, they consider the D-N element as a complex head, in accordance to what is argued for Balkan languages like Albanian, Macedonian, Bulgarian, Aromanian and Romanian, where articles are affixal. However, to spiti as a complex head in Greek - as illustrated in (15) below - is significantly harder to justify on independent grounds; we just note this issue without further discussing it here.

\section{Campos \& Stavrou's account (irrelevant details omitted)}

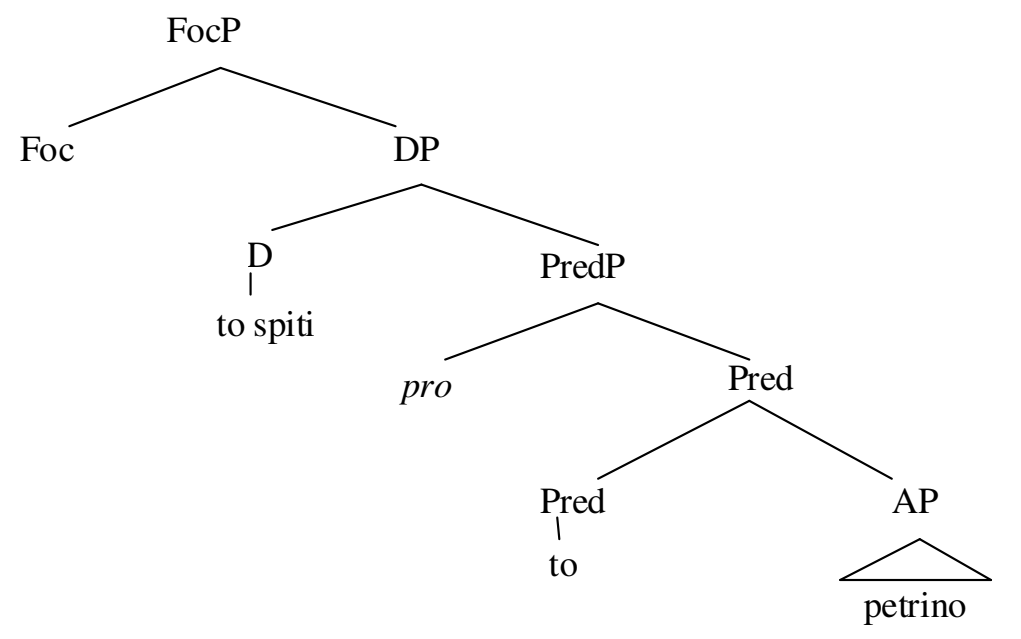

Now, D-A-D-N orders result as follows (Campos \& Stavrou 2004: 163):

"the presence of pro [...] seems to block movement of the AP to [Spec, FocP]. Thus head-movement is the only option to reach FocP. The adjective moves as a head from $\mathrm{A}$ to Pred (picking up the determiner) [...] to $\mathrm{D}$ 
(incorporating to the [D-N compound] head) [...] and then it excorporates to Foc". Therefore, like in all other analyses of DS so far, an asymmetry between the two basic word orders for DS is posited, with D-A-D-N orders resulting from movement of adjectival material to a nominal Foc(us) projection. However, D-A-D-N orders can hardly be said to have a focus reading, even more so one absent in D-N-D-A orders. Moreover an asymmetry between D-N-D-A and D-A-D-N orders cannot be empirically motivated, either, as we will see in sections 4.5 and 4.6. What is more, Campos and Stavrou propose - as is the case in all the other accounts - that the structure of monadic DPs is fundamentally different from that of DS: for instance, they take the $\mathrm{N}$ in DS to form a complex head with the first D, under the high D node, as in (15). Finally, we will take issue with their arguing that the adjective in DS is a predicative AP and show the empirical advantages of moving away from such a thesis. In general, as this analysis differs only to a small degree from the one presented in this paper - however crucially - we will be comparing the two approaches throughout the rest of this paper.

\section{AN ALTERNATIVE ANALYSIS}

We will now present an account that captures the predicative nature of DS while accounting for the word order facts with a minimum of assumptions, 
actually taking the fact that DS has a restrictive / predicative interpretation as our point of departure. In order to achieve our goal, we will not argue for a restrictive relative clause. Instead, we will claim that DS is a $\boldsymbol{D P}$ predication structure, in a vein similar to that of Campos \& Stavrou (2004). Unlike them, however, we will not argue for a PredP constituent inside DS constituents.

\subsection{DS and its kin}

Introduced in section 2.2, the relation between the restrictive and the predicative interpretations of DS is in need of further elucidation in the form of examples (16-17) below. In these examples we will try to illustrate that a D-A constituent can stand as an elliptical DP in predicative environments with a copula, but not within a relative clause. As judgements are subtle, contexts are provided.

(16) Context: The personnel of an institute consists of researchers ('erevnites') and teaching staff. In this particular institute some of the personnel are competent and some are incompetent. A number of people have just left the institute and someone comments:

(a) i erevnites i ikani efighan. DS the researchers the competent left 
(b) i erevnites pu itan (??i) ikani efighan. restr. rel the researchers that were the competent left.

'The researchers who were the competent ones left.

(c) $\mathrm{i}$ erevnites itan i ikani. with copula the researchers were the competent

'The researchers were the competent ones.'

(17) Context: The job selection process in company $\mathrm{X}$ is a two-day long process; it involves both a lot of waiting ('anamoni') and participating in different meetings, interviews etc. in different locations far apart from each other. The two days are over and the process has just finished. A candidate says to another:

(a) ?i anamoni i eknevristiki elixe. $D S$ the wait the irritating finished

(b) i anamoni pu itan (*i) eknevristiki elixe. restr. rel the wait that was the irritating finished 'The wait, which was the irritating thing, finished.'

(c) ?i anamoni itan i eknevristiki. with copula the wait was the irritating 'The wait was the irritating thing.'

Let us clarify examples (16-17) above. In (16) an adjective combines with the concrete noun erevnitis ('researcher') in three distinct 
environments, whereas in (17) with a deverbal / event noun, anamoni ('wait'). The environments respectively, as already mentioned, are:

1. Determiner Spreading: (16a), (17a).

2. Restrictive relatives with a referential predicate, characterising a referential 'head' (cf. the man who was the responsible one has fled): (16b), (17b).

3. A copular structure with a DP predicate of the D-A form; this is the standard way of expressing noun ellipsis in Greek; therefore $i$ ikani simply means 'the competent ones', see also section 4.6.

In (16), the combination of D-A $i$ ikani ('the competent ones') with a concrete noun is possible in (16a) and (16c), but very deviant within a restrictive relative. Similarly, turning to (17) we observe along with Manolessou (2000: Ch.4) that DS is anomalous with deverbal nouns such as anamoni ('wait') (17a). ${ }^{13}$ Nevertheless, (17a) and (17c) are once more much better than (17b), where D-A i eknevristiki ('the irritating one') is embedded within a relative clause. Concerning (17a) in particular, it indeed sounds quite odd unless properly contextualised; however, it is anything but grammatically marginal, a fact also indicated by the multitude of hits that Google searches for "D-A cíval” ( 'is') and "cívaı D-A.” yield. Finally, (16b) 
and (17b) are perfect when the predicate they involve is not referential (e.g. without the article). ${ }^{14}$

In other words, a D-A constituent seems incompatible with restrictive relative contexts, although it works fine as part of Determiner Spreading and as the elliptical DP ('referential') predicate inside copular predication structures. This is particularly instructive because if, as in Alexiadou \& Wilder (1998), DS syntactically involved a reduced relative clause, then we would not expect the contrast in acceptability between Determiner Spreading and relatives with D-A.

More importantly, and as is made clear especially in (16c) and (17c) above, DS does not consist of an AP constituent with an adjective agreeing for definiteness, as argued in previous analyses, but a D-A constituent that is an elliptical DP. This is why in the aforementioned examples these can be used as referential predicates, although no overt noun is present. The fact that D-A constituents are elliptical DPs is also evident from the translations

of these examples: cf. the translation of (16c) as 'The researchers were the competent ones'. We will return to this matter in section 4.6.

\subsection{The Determiner in Determiner Spreading}

DS has been shown to be a predicative relation, more specifically, a relation between a DP subject and a DP predicate. In other words, the relationship between constituents like to spiti and to meghalo in to meghalo 
to spiti is that of a DP predicate to its subject. Hence, and deferring discussion of the nature of the elliptical DP to meghalo until section 4.6, our proposed configuration for DS can be either:

[DP [DP-subject to meghalo] [D' to spiti]]

or

[DP [DP-subject to spiti] [D' to meghalo]]

(19) Phrase marker for [DP [DP-subject to meghalo] [D' to spiti]]

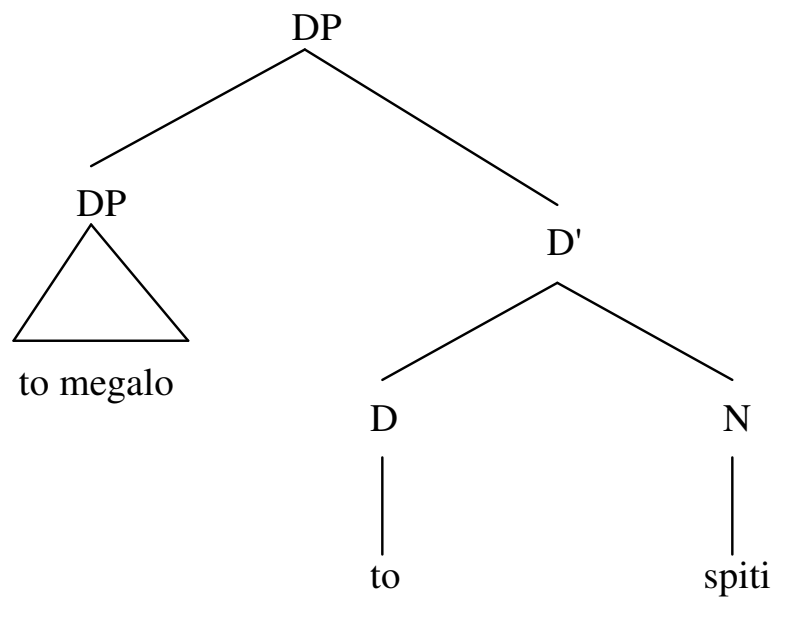

The idea that Determiner Spreading contains two constituents with one of them in SpecDP, belongs to Horrocks \& Stavrou (1986). ${ }^{15}$ This is taken to be a predicative configuration, where the DP in SpecDP acts as the subject within the DP containing it. The general idea is, in principle, in concord with theories of syntactic predication such as Stowell's (1981) 
'small clause' analysis, the small clause being the whole DP here, and Williams' (1994) subject-in-Spec configuration for predication. As in Campos \& Stavrou (2004), the D head of the larger constituent acts as the predication operator, the second to (of 'to spiti') in the example (19) above.

The above would lead us to a paradoxical situation wherein the D heading the DS constituent (the 'predicate' one) is also the predication operator: the D heading the whole DS constituent would be referential and predicative at the same time. However, D heads of 'monadic' DPs hardly display any predicative properties; moreover there is a lot of evidence that the SpecDP of 'monadic' DPs is an A' position reserved for DP-internal foci, topics (Horrocks \& Stavrou, 1987) and demonstratives (Stavrou \& Horrocks, 1989; Campbell, 1996; Panagiotidis, 2000) in Greek; the specifier of monadic DPs can also serve as an escape hatch for DP-internal wh-words.

Summarising, we are claiming here that while the D in monadic DPs is just referential, with its specifier being an $\mathrm{A}^{\prime}$ position, the $\mathrm{D}$ relating two DPs in DS appears to possess both referential and predicative properties, with its specifier hosting the subject of predication, hence an A-position. ${ }^{16}$

There are three ways to resolve this paradox. A first one, from Panagiotidis (2008) is the only slightly different analysis that there is a variety of Determiner (let's call it $\mathrm{D}_{\text {pred }}$ for lack of a more suitable label) in Greek bearing (an) interpretable feature(s) that enable(s) it to mediate in a predicative relation between its specifier (the subject of predication) and the 
NP in its complement. Hence, $\mathrm{D}_{\text {pred }}$ to would differ from its homophonous (in Greek) D to, which is only referential, in bearing (an) additional interpretable feature(s) making it also predicative. Note here that the homophony between $\mathrm{D}_{\text {pred }}$ and $\mathrm{D}$ would be a morphological accident of Greek, if something along the lines of Campos \& Stavrou (2004) is correct, namely that, for instance, Romanian cel is a genuine instance of $\mathrm{D}_{\text {pred }}$.

A second solution, one that better matches the semantics of DS as understood here, would be along the following lines: when a DP is merged as the specifier of a DP constituent, the predicative interpretation characteristic of DS is triggered. On the other hand, when a D-like constituent is copied from within the DP and merges with D, no such interpretation is possible, and the moved material at SpecDP is in an A'position. This hypothetical state of affairs is illustrated below:

$$
\mathrm{DP}_{2} \text { at SpecDP externally merged } \rightarrow \text { subject of predication }
$$

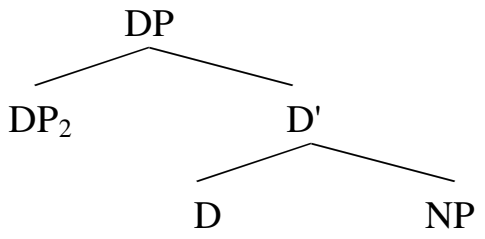

$\mathrm{DP}_{2}$ at SpecDP copied from within $N P \rightarrow$ in an $A^{\prime}$-position

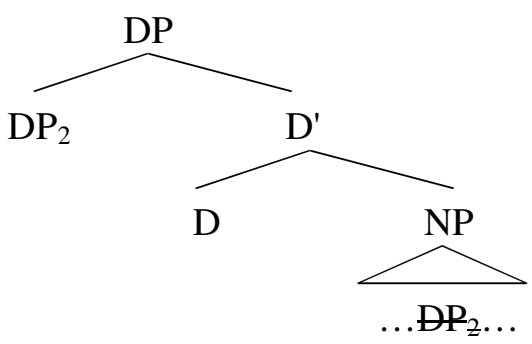


A third analysis, would have us split DP into at least a 'nominal C' and 'a nominal Infl' layer. DS would then target the specifier of this 'nominal Infl', which could be equated to Campos \& Stavrou's (2004) nominal Pred category, whereas the 'nominal C' position would still act as an A' position. See, once more, Horrocks \& Stavrou (1987) as well as Giusti (1995) for D as a nominal Inflection (hence SpecDP as an A position), while Campbell (1996) and Den Dikken (2001) contain some further discussion. ${ }^{17}$ According to this line of thinking, the availability of SpecDP in Greek as both an $\mathrm{A}^{\prime}$ position for operators (demonstratives, focused genitives) and topics and as an A position for subjects of predication would in fact constitute evidence for two D projections. This is not as easy to establish as one might think: for instance, non-dislocated possessors are always postnominal in Greek, unlike the English "Tom's diner". Furthermore, it is also true that, for some speakers, wh-extraction out of a DP with DS is much worse than extraction from a monadic DP, as in (22) below. This would suggest that SpecDP can host a subject, as an A position, while simultaneously blocking an A' operation, wh-extraction. Still, the evidence is not that clear-cut to argue for a single D-layer. Consequently, it is hard at this point to decide between the accounts outlined above.
a. $\quad$ tinos $\mathrm{i}_{\mathrm{i}}$ ides
[to petrino
spiti
$\left.t_{\mathrm{i}}\right]$ ?
whose saw. $2^{\text {nd }} \mathrm{PL}$ the of.stone house 
b. ?*tinos ides [to petrino to spiti $\left.t_{\mathrm{i}}\right]$ ?

whose saw. $2^{\text {nd }} \mathrm{PL}$ the of.stone the house

'Whose stone house did you see?'

Related to the above is the question of why DS is unavailable in Romance languages, where elliptical DPs with adjectives ('D-A'), and noun ellipsis in general, are also available. ${ }^{18}$ In brief, why are DP predicative structures only possible in Greek and related languages, as far as we know? Depending on our choice of analysis this could be either down to

a) unavailability of $D_{\text {pred }}$ category in Romance; this is what Campos \& Stavrou (2004) and Panagiotidis (2008) would suggest;

b) the interpretive component in Romance being indifferent to the derivational history of SpecDP and thus unable to interpret it as a subject-of-predication;

c) Romance DPs being single-layered. ${ }^{19}$

We hope that further research will resolve which of the three ways of understanding the predicative structure of DS is empirically superior.

\subsection{The nature of the DS subject}

It is now important to clarify a problem concerning the nature of the DS subject. ${ }^{20}$ Although the predicate in DS is referential, nothing in principle would prevent indefinite subjects or bare (plural) subjects from showing up 
in SpecDP, yielding instances of DS like in examples (1b) and (2b), repeated below as (23).

a. *(*Ena)spiti to meghalo
a / one house the big
b. $*(*$ Ena $)$ meghalo to spiti.
a / one big the house

The ungrammaticality of (23) can be traced back to the peculiarities of Greek subjects. First of all, Greek generally does not tolerate bare plurals as subjects. In generic sentences, for instance, subjects have to be headed by the definite article ${ }^{21}$ in this respect Greek resembles Italian as discussed in Longobardi (1994). The same holds for any nominal constituent not headed by the definite article, e.g. non-focused preverbal mass or abstract nouns in the singular, such as xronos ('time'). Actually, the only way to force preverbal sentential subjects headed by the null indefinite article in Greek is by D-linking them, and this almost exclusively in the journalese register. Furthermore, DPs headed by the null indefinite determiner are absolutely unacceptable as subjects of small clauses, as exemplified in the context of a copular sentence (24a) and in that of a consider-construction (25a). Interestingly, indefinite subjects headed by the 'indefinite article' enas, mia, ena ('a / one'), are also out as subjects of sentences (24b) and small clauses (25b), unless interpreted as numerals or as D-linked / specific. ${ }^{22}$ 
(24) a. *(O) xronos ine politimos.

The time is valuable.

'Time is valuable.'

b. Mia falena ine orea.

one whale is pretty

'One / a (specific) / *a whale is pretty.'

(25) a. Theori [*(ton) kafe vlavero]

considers the coffee harmful

'She / he considers coffee harmful.'

b. ?Theori [enan kinigho fonia]

considers one hunter killer

'S/he considers one / a (specific) / *a hunter a killer.'

Indefinite subjects with enas, mia, ena are much better in sentences, (24b) and (25b), than in small clauses, (24a) and (25a). This is probably a 'Diesing effect' (Diesing 1992): maybe small clauses do not contain (enough) structure in a 'Discourse Domain' (Grohmann 2003) for their subject to raise into so as to get a specific reading - contrary to what happens in full clauses. Therefore, specific interpretation of indefinite subjects with enas, mia, ena is impossible to license syntactically either because of the deficiency of, say, the small clause's discourse-complementiser field or because small clauses have no discourse-complementiser field. In any case, 
DPs definitely lack a complementiser field, hence we predict such generic and indefinite subjects to be impossible in the SpecDP - in Determiner Spreading, in other words.

An important point in our analysis is that it does not postulate any movement operations: the subject DP merges directly with the predicate DP, in its specifier. Because any DP can be a predicate and of course any 'definite' DP, being itself referential, can be a subject, the ordering of DPs appears to be free in DS, although in each case different base-generated predicates describe different base-generated subjects. So, in [DP [DP-subject to meghalo] [D' to spiti]], the meaning is roughly 'the big one which is the house', or similar, whereas [DP [DP-subject to spiti] [D' to meghalo]] means something along the lines of 'the house which is the big one'. The difference is subtle, but present. Still, this is not the whole story: more needs to be said about the nature of the elliptical DPs, of which we see only the determiner and the adjective. This is the focus of Section 4.6.

\subsection{DS without ellipsis?}

Before moving on, let us briefly address a valid question, that is, whether DS can involve two DPs neither of which is elliptical. The answer is yes, at least in Greek. Examples include the following (adapted from StavrouSifaki, 1995: 218 - see also Campos \& Stavrou, 2004): ${ }^{23}$ 
(26) (a) o Solomos o piitis.

the Solomos the poet

'Solomos the poet.'

(b) o aetos to puli.

the eagle the bird

'Eagle, the bird.'

(c) esis i nei kalitehnes.

you the young artists

'You young artists.'

In (26a), a proper name DP combines with another one; in (26b) two definite DPs combine together; in (26c) it is a pronoun and a definite DP. The semantic interpretation of all the examples in (26) is almost identical to that of DS, involving predication between DPs. Stavrou-Sifaki (1995) dubs the phenomenon illustrated above epexegesis and she teases it apart from apposition, which inter alia forces an intonation break between the two DPs. She moreover offers a very similar analysis to ours, also unifying epexegesis with Determiner Spreading, a claim reconfirmed in Campos \& Stavrou (2004). Therefore, by extending our analysis to epexegesis, we would represent (26c), for instance, as [DP [DP-subject esis] [D' i nei kalitehnes]] ('you young artists'). Details aside, DP predication is anything but a phenomenon restricted to just D-A sequences. DPs with referential predication are run-of- 
the-mill in Greek; labels such as 'DS' or 'epexegesis' are merely descriptive, evocative of the type of constituents involved. ${ }^{24}$

\subsection{Deriving the interpretive effects}

We already saw in example (8) in section 2.2, and throughout the discussion in this section, that Determiner Spreading can have a restrictive reading, i.e. pick out proper subsets from the superset described by its predicate DP. At the same time, we also encountered the availability of predicative readings for DS. How are the two related to each other? Although the semantics of the structure is actually beyond the scope of this contribution, an informal sketch will be provided here for exposition.

Let us start with the difference between the interpretation of DS and that of an adjectivally modified 'monadic' DP, which can be expressed as follows: the interpretation of DS arises from the intersection of two sets, each described by a 'monadic' DPs, a subject and a predicate; DS is the intersection of two already restricted sets. More specifically: call S' the set of the stone things as described by the elliptical DP 'ta petrina' ('the stone ones') and $\mathrm{H}$ ' the set of the houses as described by the DP 'ta spitia' ('the houses'). Membership of these sets $\mathrm{S}^{\prime}$ and $\mathrm{H}^{\prime}$ is not only restricted by the concepts the adjective petrina and the noun spitia denote, but also by the respective Determiners $t a$ and whatever else a Greek DP, such as Num, 
contains. Determiner Spreading, a predication relation, is interpreted as the intersection of the two sets:

(27) $\mid[$ ta petrina ta spitia $] \mid=\mathrm{S}^{\prime} \cap \mathrm{H}^{\prime}$

Now we need to derive the restrictive reading of DS, which, as claimed here, is a subcase of the predicative one. This task can be carried out as follows: recall that membership of the sets $\mathrm{S}^{\prime}$ and $\mathrm{H}^{\prime}$ is not only restricted by the concepts their respective lexical material (adjective and noun) denotes, but also by their determiners, Num heads and so on. ${ }^{25}$ Now, given the various contextual factors conspiring with syntactic structure to yield the extension of (definite or other) DPs, it may happen that one of the sets, let's say the subject DP's extension, is a proper subset of the other one, with $\mathrm{S}^{\prime} \subset \mathrm{H}^{\prime}$; this is the restrictive interpretation of DS, the only interpretation according to Kolliakou's Polydefiniteness Constraint (2004: 272-276). Of course, in a situation where $\mathrm{S}^{\prime} \subset \mathrm{H}^{\prime}$ holds, it is also trivially true that the whole $\mathrm{S}^{\prime}$ is the intersection of itself with H'. Informally, a DP with Determiner Spreading like ta petrina ta spitia can be interpreted either predicatively as 'the stone ones that have the property of being the houses', as from (27), or restrictively as 'the stone ones of the houses'. Given that, a monadic DP ta petrina spitia ('the stone houses') can also have an interpretation similar to that indicated in (27), the pragmatically preferred reading for DS, which contains more structure, is often the restrictive one, pace matters of Focus and intonation. 
To summarise, DS is a DP predication structure with a DP subject predicated over a DP predicate. The resulting relation, one of two sets intersecting, is the expected one. A subcase of this relation is when the intersection is one of the (sub)sets itself - this is the restrictive interpretation. Crucially, we have taken for granted so far that D+A constituents are DPs. The reasons why are explained in the next subsection. $^{26}$

\subsection{The $D+A$ constituent is an elliptical DP}

Constituents like to meghalo ('the big one'), far from being APs or language-specific curiosities, are nothing but elliptical DPs comprising a semantically (i.e. non-descriptive) and phonologically null noun $e_{\mathrm{N}}$ (Kester, 1996; Corver \& Delfitto, 1999; Panagiotidis, 2002 and elsewhere). ${ }^{27}$ The presence of $e_{\mathrm{N}}$ in a number of seemingly nounless DP constituents syntactically licenses the determiner and provides a trivial predicate for it to range over. Finally, despite its not denoting a concept, $e_{\mathrm{N}}$ may mark other LF interpretable features, such as gender (cf. Heim, 2008).

What this means in our case is that the D-A constituent functions quasi-pronominally, it being an elliptical DP of the form [D to [FP [AP petrino] $\mathrm{F}\left[\mathrm{N} e_{\mathrm{N}}\right]$. So, the presence of an article before an adjective does not 
constitute a definiteness agreement marker on the adjective, exactly as it does not before the adjective ikani in (16c) either.

The resulting structures are given in (28) and (29) below.

(28) $D-A-D-N$

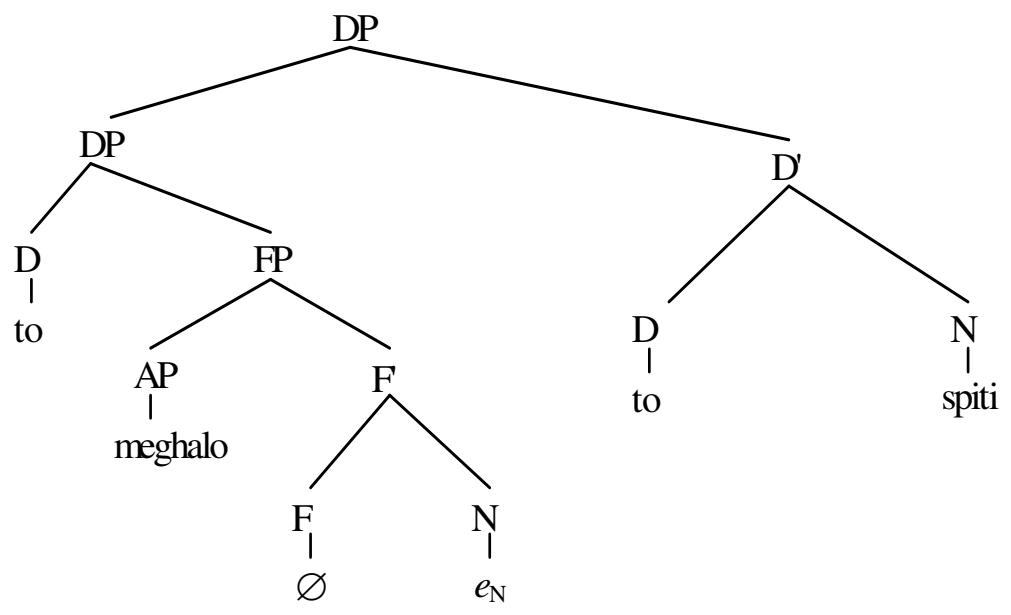

(29) $D-N-D-A$

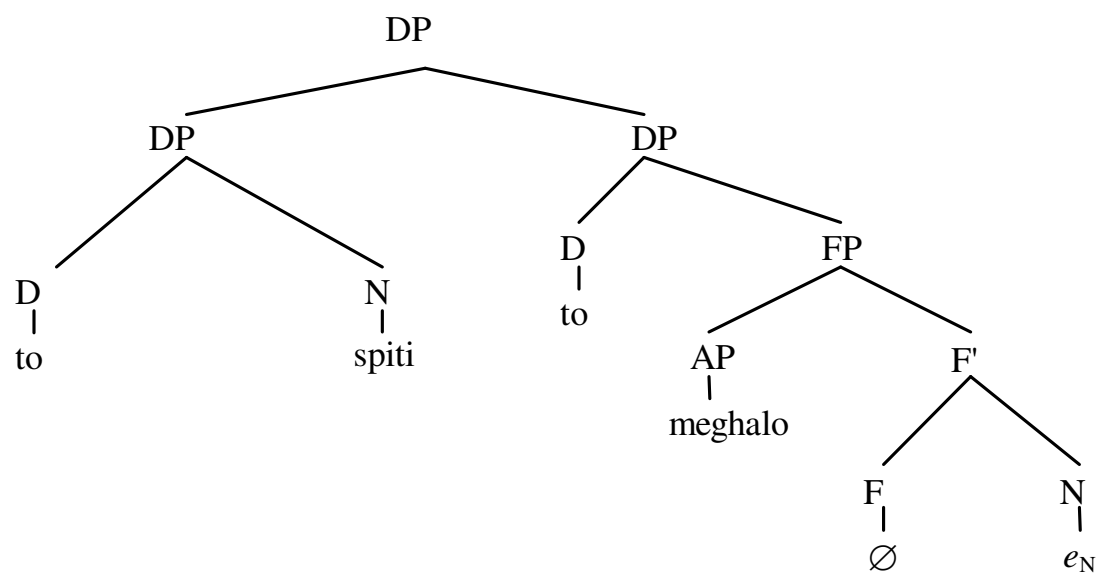

This account is empirically superior to the ones arguing the adjective within

DS to be an AP and we will argue for this concentrating on Campos \& 
Stavrou (2004). Campos \& Stavrou claim that the adjectival constituents within DS must be APs, as discussed in 3.4; adjectives in D-N-D-A orders behave as full APs, while they head-move all the way to a highest Foc head in D-A-D-N orders. In support of this purported asymmetry, they cite the examples below, their (51); judgements are theirs:

(30) Adjective heads vs. APs?

a. *to toso / poli / pjo oreo to vivlio the so / very/ more nice the book

b. to vivlio to toso / poli / pjo oreo the book the so / very more nice 'the very nice / nicer book'

c. $*_{\mathrm{i}}$ perifani gia ta pedia tis $\mathrm{i}$ mana the proud of the children her the mother d. $\mathrm{i}$ mana $\mathrm{i}$ perifani gia ta pedia tis the mother the proud of the children her 'the mother proud of her children'

Although they star examples (30a) and (30c), this is not a judgement other native speakers share. To the extent that (30c) should be given a '?', this 
must be attributed to parsing reasons, due to the subject DP $i$ perifani gia ta pedia tis ('the proud of her children') being so much heavier than the DP predicate $i$ mana ('the mother') - not to an inability of the head-moved adjective perifani ('proud') to pied-pipe its argument to the Focus domain. Now, in (30a) the difference in heaviness between the DP subject to toso oreo ('the so nice') and its DP predicate to vivlio ('the book') is much smaller, and this is why the said parsing effect is virtually imperceptible (and very far from deserving a star), in this case. At the end of the day, what the examples in (30) actually show is that D-N-D-A structures are indeed symmetrical to D-A-D-N ones and that the same D-A constituent is at play in both orders.

This takes us to whether this D-A constituent is an AP or, as argued here, an elliptical DP with an adjective. Campos \& Stavrou (2004: 162-3) argue it to be a predicative AP on the basis of intensional adjectives (31a), circumstantial adjectives (31b) and adjectives that form part of a $\mathrm{A}+\mathrm{N}$ compound (31c) being banned in DS - see also Manolessou (2000: Ch. 4). These are illustrated in the example below - adapted from example (49) in Campos \& Stavrou (2004):

(31) Which adjectives are banned from DS?

a. $*_{\mathrm{o}}$ tromokratis o ipotithemenos the terrorist the alleged 
b. $*_{\mathrm{O}}$ proedros o proin the president the former

c. ?to astiko to leoforio the urban the bus (urban bus)

(32) How do the above D-A constituents fare as referential predicates?

a. $*_{0}$ tromokratis ine $[0$ ipotithemenos $]$

the terrorist is the alleged

'The terrorist is the alleged one'.

b. $*_{\mathrm{o}}$ proedros ine $[\mathrm{o}$ proin $]$

the president ine the former

'The president is the former one'

c. ?to leoforio ine [to astiko]

the bus is the urban

'The bus is the urban one.'

Example (31) illustrates Campos \& Stavrou's claim that in D-N-D-A orders the ' $\mathrm{A}$ ' is of a predicative character, a predicative AP. We agree that (31c) is marked and that the presence of intensional and circumstantial adjectives (31a-b) is ungrammatical in DS. However, looking at (32), we notice that elliptical DPs with intensional (32a) and circumstantial (32b) adjectives are 
also impossible as referential predicates in a copular environment. This suggests that the argument can go either way: whatever bans these two classes of adjectives from within DS also bans them from being referential predicates in copular configurations. In other words, they are banned from DS not (necessarily) because DS involves predicative APs.

\subsection{Deriving the word orders}

A serious issue with most of the previous syntactic accounts is deriving the full set of different word orders described in section 2 without overgenerating. Despite the fact that recursion can probably do the trick for the evidence presented under (3) in Alexiadou \& Wilder's (1998) and Giusti's (2003) analyses, accounting for the grammaticality of (3) and (6) as opposed to (5) - repeated below for convenience - can be less straightforward.

(a) To meghalo to petrino to spiti. the big the of.stone the house

(b) To meghalo to spiti to petrino. the big the house the of.stone

(c) To petrino to spiti to meghalo. the of.stone the house the big 
(d) To petrino to meghalo to spiti

the of.stone the big the house

(e) To spiti to meghalo to petrino.

the house the big the of.stone

(f) To spiti to petrino to meghalo.

the house the of.stone the big

'The big stone house.'

(5) (a) *To spiti meghaloto petrino.

The house big the of.stone

(b) *To spiti to meghalo petrino.

The house the big of.stone

'The big stone house.'

(6) (a) To meghalo to petrino spiti.

The big the of.stone house

(b) To meghalo spiti to petrino.

The big house the of.stone

'The big stone house.'

In (3), we saw that all the combinatorial possibilities (six in the case of two adjectives and a noun) for DS are grammatical if an article precedes each lexical element of the constituent. In this case, three DPs are contained in the DS constituent, a DP itself. One of them, informally the rightmost, is 
the DP predicate, say to meghalo $e_{\mathrm{N}}$ in (3c). Its subject is yet another DS constituent, to petrino $e_{\mathrm{N}}$ to spiti, which in its own turn is made of a DP predicate to spiti, and its subject to petrino $e_{\mathrm{N}}$. This state of affairs is depicted in (33) below, where the structure of (3c) is given. It is hence worth noting here that the word order 'freedom' displayed in (3) is by no means an indication of non-configurationality but, rather, the result of DPs (including DPs displaying DS) being free to function as subjects.

(33) DS with two adjectives (or 'the effects of recursion')

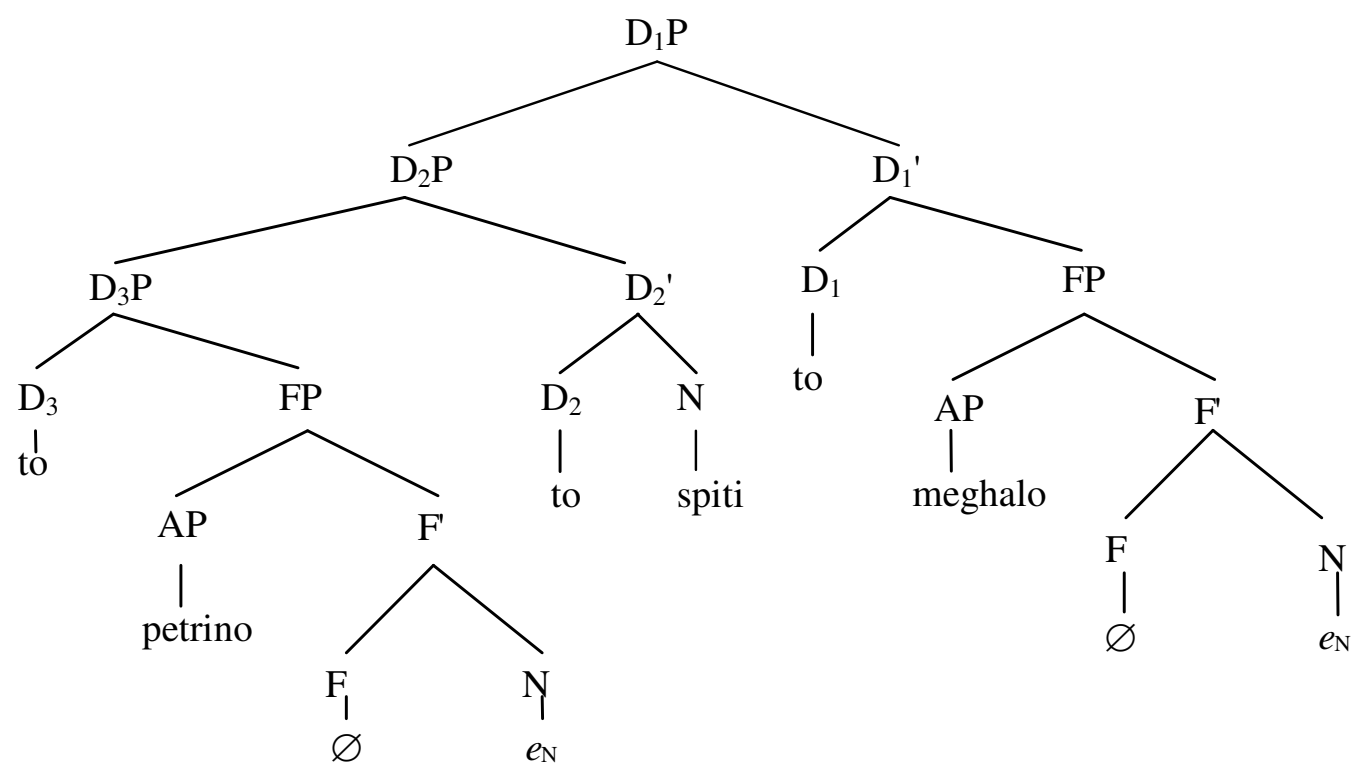

In the account presented here, the contrast between (5) and (6) can also be satisfactorily captured with no added assumptions. In (6), two DPs, one subject and one referential predicate, are involved in DS and nothing 
prevents either or both of them to possess a more complex structure, such as one including adjectives, demonstratives, possessors and so on. The examples in (6) illustrate only one of these options, namely the non-elliptical DP involving an AP. So, (6a) is analysed as [DP [DP-subject to meghalo $e_{\mathrm{N}}$ ] [D' to petrino spiti]] and (6b) as [DP [DP-subject to meghalo spiti] [D' to petrino $\left.e_{\mathrm{N}}\right]$ ] - see also (28) and (29).

Turning to (5) now, if the article to marks the boundaries between the DPs in DS, the ungrammaticality of (5a) becomes obvious, as it would take the ungrammatical DP * to spiti meghalo as subject. However, *to spiti meghalo is a DP displaying the D-N-A order, which we already saw in (4b) to be banned in Greek. As for the unacceptability of (5b), we wish to note that an elliptical DP with two, as opposed to one, APs is not permitted either, anyway. This is already discussed for English in Sadler \& Arnold (1994). Whatever the principled explanation is, this entails that (5b) is ungrammatical because it contains the ungrammatical elliptical DP *to meghalo petrino $e_{\mathrm{N}}$ as its DP predicate.

Before wrapping this section up, let us comment that our analysis helps shed light on the observation made by Manolessou (2000: Ch. 4) on the frequency of DS. After a corpus study of written Modern Greek, she claims that DS is found in informal texts and written texts emulating speech more frequently than in texts representing a higher register or style. This is a potentially serious problem if, as according to all the previous analyses, DS 
contains more complex structure than monadic DPs. On the other hand, in our analysis, this is a fact that can be captured along the lines of parsing effort. To wit, a DP with Determiner Spreading typically consists of at least two monadic DPs, with one of them elliptical. This means that a number of modifiers can be packaged within a single DS structure, as in examples (3), (6), but also (30). Of course, it is also perfectly possible to package a number of modifiers within monadic DPs: a monadic DP with two adjectives in (4a) - repeated below - is absolutely fine.

(a) To meghalo petrino spiti.

The big of.stone house

Having said that, choosing DS to package more than one modifier presents the added advantage that every instance of the article marks the boundary of a new DP subconstituent, making parsing easier. If this line of reasoning is on the right track, then we can probably explain why we find DS more commonly in speech, where parsing takes place in real time only, especially with nouns taking two modifiers or more. The parsing differences between 'monadic' and DS DPs is therefore an interesting topic for future research.

\section{CONCLUSION}

We have offered a novel account of Determiner Spreading in Greek suggesting it be unified with epexegesis, along the lines of Stavrou-Sifaki 
(1995), with both phenomena being instances of DP predication. The analysis presented here has a number of advantages over previous ones. First of all, it explains the 'free' distribution between D-A-D-N and D-N-D-A in DS. It also captures all the different orders in (3) and (6), while excluding (5), without introducing novel assumptions. The restrictive interpretation of the phenomenon is argued to be a pragmatically induced subcase of its predicative function. DS is conceived as a subject-predicate configuration, a relation between a SpecXP (the subject) and a predicate: no special functional categories are postulated, no reduced relative CPs are understood to be embedded within the DP, no unidentified categories are required and, to the extent this is a goal, no movement operations (and their triggers) are necessary.

Most crucially in terms of methodological parsimony and commitment to Occam's Razor, DS has clearly been shown not to be a particular construction, a configuration at the periphery of grammar. On the contrary, it has been argued to occur when elliptical DPs are involved in referential predication and, essentially, to be identical to epexegesis: LF can see both the highest category (D) and the internal structure (subjectpredicate) thereof and interprets both accordingly.

\section{REFERENCES}


ABNEY, S. P. 1987. The English noun phrase in its sentential aspect. Ph.D. thesis, MIT.

ALEXIADOU, A. \& WILDER, Ch. 1998. Adjectival modification and multiple determiners. In Alexiadou, A. \& Wilder, Ch. (eds.), Possessors, predicates and movement in the DP. Amsterdam: Benjamins, 303-332.

ALEXIADOU, A. \& STAVROU, M. 1998. On the relation between 'strength' and morphological richness: crosslinguistic asymmetries in noun movement. Paper delivered at the 8th International Conference on Morphology, Budapest.

ANDROUTSOPOULOU, A. 1994. The distribution of the definite determiner and the syntax of Greek DPs. In Proceedings of the 30th regional meeting of the Chicago Linguistic Society. Chicago: University of Chicago Press, 16-29.

ANDROUTSOPOULOU, A. 1995. The licensing of adjectival modification. In Proceedings of the 14th WCCFL. Stanford: CSLI.

BOWERS, J. 1993. The syntax of predication. Linguistic Inquiry 24: 591656.

CAMPBELL, R. 1996. Specificity operators in SpecDP. Studia Linguistica 50, 161-188.

CAMPOS, H. \& STAVROU, M. 2004. Polydefinite constructions in Modern Greek and in Aromanian. In Mišeska Tomić, O. (ed.) Balkan Syntax and Semantics. Amsterdam: Benjamins, 136-173. 
CHOMSKY, N. 1993. A minimalist program for linguistic theory. In Hale,

K. \& Keyser, S. J. (Eds.) The View from Building 20. Cambridge, MA:

MIT Press. 1-52

CHOMSKY, N. 2000. Minimalist Inquiries: The Framework. In Martin, R., Michaels D. \& Uriagereka, J. (Eds.) Step by Step: Essays in Minimalist Syntax in Honor of Howard Lasnik. Cambridge, MA: MIT Press. 89-155

CINQUE, G. 1994. On the evidence of partial N-movement in the Romance

DP. In Cinque, G. et al. (eds.), Paths towards universal grammar.

Washington D.C.: Georgetown University Press, 85-110.

CORVER, N. \& Delfitto, D. 1999. On the nature of pronoun movement. In

Van Riemsdijk, H. (ed.), Clitics in the languages of Europe, 799-861.

DELSING, L.-O. 1988. The Scandinavian noun phrase. Working Papers in Scandinavian Syntax 42, 57-79.

DEN DIKKEN, M. 1998. Predicate inversion in DP. In Alexiadou, A. and

C. Wilder (eds.) Possessors, Predicates and Movement in the Determiner Phrase. Amsterdam: John Benjamins, 177-214.

DEN DIKKEN, M. 2001. 'Pluringulars', pronouns and quirky agreement.

The Linguistic Review 18, 19-41.

DIESING, M. 1992. Indefinites. Cambridge, Mass.: MIT Press.

DOBROVIE-SORIN, C. 2000. (In)definiteness spread: from Romanian genitives to Hebrew construct state nominals. In Motapanyane V. (ed), 
Comparative studies in Romanian syntax. Amsterdam : North Holland Elsevier.

EMBICK, D. \& MARANTZ, A. 2008. Architecture and blocking. Linguistic Inquiry 39, 1-53.

EMBICK, D. and NOYER R. 2001. Movement Operations after Syntax. Linguistic Inquiry 32, 555-595.

GIANNAKIDOU, A. \& STAVROU, M. 1999. Nominalization and ellipsis in the Greek DP. The Linguistic Review 16, 295-331.

GIUSTI, G. 1995. A unified structural representation of (abstract) case and article. In Haider H., Olsen S. \& Vikner S. (eds.), Studies in comparative Germanic Syntax. Dordrecht: Kluwer, 77-93.

GIUSTI, G. 1997. The Categorial Status of Determiners. In Haegeman L. (ed.), The New Comparative Syntax. London: Longman, 95-123.

GIUSTI, G. 2003. The functional structure of noun phrases: a bare phrase structure approach. In Cinque, G. (ed.) Functional Structure in DP and IP. Vol. 1. Oxford: Oxford University Press, 54-90.

GROHMANN, K. 2003. Prolific Domains. On the anti-Locality of movement dependencies. Amsterdam: Benjamins.

HANKAMER, J. and MIKKELSEN, L. 2005. When movement must be blocked: a response to Embick and Noyer. Linguistic Inquiry 36, 85125. 
HEIM, I. and KRATZER A. 1998. Semantics in Generative Grammar. Oxford: Blackwell.

HEIM, I. 2008. Features on bound pronouns. In Harbour D., Adger D. \& S Béjar (eds.), Phi-Theory: phi-features across modules and interfaces. Oxford: OUP. 35-56.

HELLAN, L. 1986. The headedness of NPs in Norwegian. In Muysken, P. \& Van Riemsdijk, H. (eds.), Features and projections. Dordrecht: Foris. $89-122$

HOLMBERG, A. and NIKANNE, U. 2002. Expletives, Subjects, and Topics in Finnish. In Svenonius, P. (ed.), Subjects, Expletives and the EPP. Oxford: Oxford University Press. 71-105.

HORROCKS, G. \& STAVROU, M. 1986. Mia proti prosengisi ke erminia ton epithetikon prosdiorismon sta Nea Ellinika. ['A first approach and interpretation of adjectival modification in Modern Greek'] In Studies in Greek Linguistics. Proceedings of the the $7^{\text {th }}$ annual meeting of the Department of Linguistics, Faculty of Philosophy, Aristotelian University of Thessaloniki. Thessaloniki: Kyriakidis. 109-116.

HORROCKS, G. \& STAVROU, M. 1987. Bounding theory and Greek syntax: evidence for wh-movement in NP. Journal of Linguistics 23: 79108.

IHSANE, T. 2008. The layered DP. Amsterdam: Benjamins. 
KAYNE, R. S. 1994. The antisymmetry of syntax. Cambridge, Mass.: MIT Press.

KESTER, E.-P. 1996. The nature of adjectival inflection. Utrecht: OTS.

KOLLIAKOU, D. 1998. Linkhood and Multiple Definite Marking. In

Bouma, G. Kruijff G.-J. and Oehrle R. (eds.), Proceedings of the 1998

Conference on Formal Grammar, Head-Driven Phrase Structure

Grammar, and Categorial Grammar (FHCG '98), 14-22.

KOLLIAKOU, D. 2003. Nominal constructions in Greek: implications for the architecture of grammar. Stanford: CSLI Publications \& Chicago: University of Chicago Press.

KOLLIAKOU, D. 2004. Monadic definites and polydefinites: their form, meaning and use. Journal of Linguistics 40: 263-323.

LASNIK, H. 1991. On the necessity of binding conditions. In Freidin, R. (ed.), Principles and parameters in comparative grammar. Cambridge, Mass.: MIT Press, 7-28.

LARSON, R. 1999. Semantics of Adjectival Modification. Lectures presented at the Dutch National Graduate School (LOT), Amsterdam.

LARSON, R. 2004. The deep position of nominal modifiers. Talk delivered at CUNY.

LARSON, R. \& YAMAKIDO, H. 2008. Larson, R. \& Yamakido, H. 2005. Ezafe and the deep position of nominal modifiers. In McNally, Louise \& 
Kennedy, Christopher (eds.) Adjectives and Adverbs. Syntax, Semantics, and Discourse. Oxford: OUP. 43-70

LEKAKOU, M. \& SZENDRÖI, K. 2007. Eliding the noun in close apposition, or Greek polydefinites revisited. In Richard Breheny and Nikolaos Velegrakis (eds.) UCL Working Papers in Linguistics 19. 129154.

LONGOBARDI, G. 1994. Reference and proper names: a theory of Nmovement in syntax and logical form. Linguistic Inquiry 25: 609-665.

MANOLESSOU, I. 2000. Greek noun phrase structure: a study in syntactic evolution. Ph.D. thesis, University of Cambridge.

MARINIS, Th. \& PANAGIOTIDIS, Ph. 2001. Determiner Spreading as Predication. In Clairis, Ch. (ed.), Recherches en linguistique grecque. Paris: L'Harmattan

MATHIEU, E. \& SITARIDOU, I. 2002. Null head nominals, determiner spreading and the topic/focus articulation in Modern Greek. Paper presented at the 'Greek Syntax and the Minimalist seduction' workshop, University of Reading, September 2002.

NTELITHEOS, D. 2004. Syntax of Elliptical and Discontinuous Nominals. Unpublished MA dissertation, UCLA.

PANAGIOTIDIS, Ph. 2000. Demonstrative determiners and operators: the case of Greek. Lingua 110: 717-742. 
PANAGIOTIDIS, Ph. 2002. Pronouns, clitics and empty nouns.

Amsterdam: Benjamins.

PANAGIOTIDIS, Ph. 2008. Diachronic stability and feature interpretability. In Biberauer, Theresa (ed.) The limits of syntactic variation. Amsterdam \& Philadelphia: John Benjamins, 441-456

PARTEE, B. 1995. Lexical Semantics and Compositionality. In Gleitman L. and Liberman M. (eds.) Invitation to Cognitive Science; Part I:

Language. Cambridge, Mass.: MIT Press, 311-360.

RADFORD, A. 1993. Head-Hunting: on the trail of the nominal Janus. In Corbett, G. et al. (eds.), Heads in grammatical theory. Cambridge: CUP. 73-113.

RITTER, E. 1991. Two functional categories in noun phrases: evidence from Modern Hebrew. In Rothstein, S. (ed.), Perspectives on Phrase Structure: Heads and licensing. [Syntax and Semantics 25]. San Diego: Academic Press, 37-62.

SADLER, L. \& ARNOLD, D. 1994. Prenominal adjectives and the phrasal/lexical distinction. Journal of Linguistics 30:187-226.

SILONI, T. 1997. Noun Phrases and nominalizations: The Syntax of DPs. Kluwer.

STAVROU-SIFAKI, M. 1995. Epexegesis vs. apposition in Modern Greek. Epistimoniki Epetirida tis Filosofikis Sholis tu Panepistimiu 
Thessalonikis 5. Thessaloniki: Aristotle University of Thessaloniki. 215250.

STAVROU, M. 1996. Adjectives in Modern Greek: an instance of predication or an old issue revisited. Journal of Linguistics 32: 79-112.

STAVROU. M. 1999. The position and serialization of APs in the DP: evidence from Greek. In Alexiadou, A., Horrocks, G. \& Stavrou, M. Studies in Greek Syntax. Dordrecht: Kluwer. 201-225.

STAVROU, M. \& HORROCKS, G. 1989. Enklitikes kai deiktikes antonymies mesa stin OF [Enclitic and demonstrative pronouns in NP]. Proceedings of the Annual Meeting of the Department of Linguistics, Faculty of Philosophy. Thessaloniki: Aristotle University of Thessaloniki. 225-243.

STOWELL, T. 1981. Origins of phrase structure. Ph.D. thesis, MIT.

TARALDSEN, K. T. 1990. D-projections and N-projections in Norwegian. In Mascaró, J. \& Nespor, M. (eds.), Grammar in progress. Essays in honor of Henk van Riemsdijk. Dordrecht: Foris. 419-432.

WILlIAMS, E. 1994. Thematic Structure in Syntax. Cambridge, Mass.: MIT Press. 


\section{FOOTNOTES}

* We are grateful to the anonymous referees, Melita Stavrou, Io Manolessou, Richard Larson, Catherine Heycock, Kleanthes Grohmann, Brian Joseph, and Giuliana Giusti for comments, discussions and encouragement. Nevertheless, all errors, omissions and misconceptions are to be credited to the co-authors.

1 To the best of our knowledge, the term 'Determiner Spreading' was introduced by Androutsopoulou (1994). We prefer this neutral term over the more recent 'polydefinite' (Kolliakou 2003; 2004), because Greek 'definite' determiners (the $o, i$, to paradigm) are not exclusively definite in interpretation: Giannakidou \& Stavrou (1999) have shown the Greek 'definite' article to be an intensionalisation operator. Expectedly, Determiner Spreading is not a definite construction: for instance, it is possible with a generic reading. We will nevertheless continue using 'D', '(definite) determiner' and '(definite) article' throughout this paper to refer to the $o, i$, to paradigm. Regarding the Greek 'indefinite determiner', we will have very little to say about it, as this never occurs in DS structures and it does not uncontroversially belong to the syntactic category of Determiner.

${ }^{2}$ See Manolessou (2000: Ch. 4) for a detailed description and discussion.

${ }^{3}$ Articles and related markers appear in boldface throughout this section.

${ }^{4}$ FUT = "future"; SUBJ= "subjunctive". Example adapted from Kolliakou (2004: 270). Discussion here follows Kolliakou (1998; 2004) and Manolessou (2000: Ch. 4).

${ }^{5}$ We return to this observation in section 4.5 .

${ }^{6}$ See Kolliakou (2004) on the relevance of prosody in disambiguating Greek DPs.

${ }^{7}$ A further piece of evidence potentially supporting the relevance of predication in DS is the fact that only intersective adjectives can participate in it as Richard Larson (p.c.) pointed out. Very interestingly, DS with epithets such as murlos ('nutter'), kopanos ('blockhead') 
and so on is interpreted predicatively and never as restrictive. We leave this open, as relatively little is understood about the position, referential properties (but see Lasnik 1991) and feature-makeup of epithets. The interested reader is referred to the discussion in section 4.6, Manolessou (2000: Ch. 4) and Campos \& Stavrou (2004).

${ }^{8}$ As the analysis here heavily builds on the one in Marinis \& Panagiotidis (2001), we will not summarise it here. Similarly, we will not discuss the exciting alternative analyses in Larson \& Yamakido (2008) and Lekakou \& Szendröi (2008), which in part build on a previous version of the account presented here, Mathieu \& Sitaridou (2002), who elaborate on Alexiadou \& Wilder (1998), or Ntelitheos (2004), who argues for a much more elaborate structure involving focus.

9 There being no such thing as a 'Minimalist Theory': minimalist aspirations are methodologically expressible in any grammatical framework; see Chomsky (2000: 92).

${ }^{10}$ For a recent take on Scandinavian 'double definiteness' and the related differences between Swedish and Danish, see the debate in Embick and Noyer (2001), Hankamer and Mikkelsen (2005) and Embick and Marantz (2008).

11 Contrast this to the rather 'productive' nature of Mainland Scandinavian double definiteness markers -en and -et, as they can appear in the absence of den and det with interesting interpretive effects (albeit different from those of DS): compare Vitte Hus-et ('The White House') with det vitte hus-et ('the white house', e.g. on the hill). Again, see Hellan (1986), Delsing (1988) and Taraldsen (1990) for discussion.

12 The point in Manolessou (2000: Ch.4) that, diachronically, D-N-D-A predates D-A-D-N in Greek by several centuries is probably moot, see also Panagiotidis (2008: 450-452).

${ }^{13}$ Why this is the case is beyond the scope of this work: the interested reader is referred to Manolessou's work for insights. 
${ }^{14}$ See also example (32) for a correlation between DS and copular structures with elliptical DP predicates.

${ }^{15}$ Although they do not take them to be both DPs.

${ }^{16}$ The discussion here has greatly benefited from discussions with Kleanthes Grohmann and two anonymous reviewers, who we wish to thank.

${ }^{17}$ Note however that the above would not entail that we import a full clausal structure into DS, like in Alexiadou \& Wilder (1998), as we would still not have a constituent with full discourse (C) and temporal / aspectual (Infl) structure as explained in section 4.3 on illegal DS subjects

${ }^{18}$ A related issue is why * the blue one the house is ungrammatical in English.

${ }^{19}$ But this is doubtful, see Ihsane (2008).

${ }^{20}$ We are indebted to Caroline Heycock and Kleanthes Grohmann for discussing this topic with us.

${ }^{21}$ I.e. the $o, i$, to paradigm. See footnote 1.

${ }^{22}$ We treat D-linking and specificity in unison here. No theoretical claims are implied. We are grateful to an anonymous reviewer for extensive comments on a previous version of this paper.

${ }^{23}$ The structure exemplified in (26) is run-of-the-mill and is also a common way to express kinship terms with proper names in Greek: o thios (o) Nikos ('uncle Nikos'). Interestingly, Kolliakou (2004: 273-276) discusses related examples of DS with proper names, arguing them to be restrictive (as many people may share the same name). Still, as expected by now, in $o$ thios (o) Nikos ('uncle Nikos') and in the case of DS with proper names such as o Nikos o psilos ('Nikos the tall one'), the restrictive reading is not necessary. See also section 4.5

${ }^{24}$ Naturally, DS with two elliptical DPs is fine, especially as an elliptical answer to a question like "Which house would you buy?": to meghalo to petrino ('the big stone one'). 
At this point, it is also worth mentioning what an anonymous reviewer asks: is this DP configuration possible with two indefinite constituents? In other words, are [meghalo [petrino]] and [petrino [meghalo]] possible as DP-sized predication structures? The answer is possibly in the affirmative, however the above are virtually indistinguishable, both syntactically and semantically, from monadic elliptical indefinite DPs - see also section 4.6.

${ }^{25}$ For instance, see Heim and Kratzer (1998) and Heim (2008) on the interpretive role of phi-features.

${ }^{26}$ In other words, and as Campos \& Stavrou (2004) also claim, the D heading the DS constituent (the 'predicate' one) is also the predication operator. It is both referential and predicative, reminiscent of Homberg \& Nikanne's (2002) Fin, with its mixed A and A' properties.

${ }^{27}$ According to Panagiotidis (2002), semantically empty nouns, whether phonologically null $\left(e_{\mathrm{N}}\right)$ or not (one in English), are also present within pronouns - again argued to be full DPs - and they are the ones triggering pronominal reference. 